\title{
Cross sectional study estimating prevalence of heart failure and left ventricular systolic dysfunction in community patients at risk
}

\author{
O W Nielsen, J Hilden, C T Larsen, J F Hansen
}

\begin{abstract}
Objective-To examine a general practice population to measure the prevalence of signs and symptoms of heart failure (SSHF) and left ventricular systolic dysfunction (LVSD).

Design-Cross sectional screening study in three general practices followed by echocardiography.

Setting and patients-All patients $\geqslant 50$ years in two general practices and $\geqslant 40$ years in one general practice were screened by case record reviews and questionnaires $(n=2158)$, to identify subjects with some evidence of heart disease. Among these, subjects were sought who had SSHF $(n=115)$. Of 357 subjects with evidence of heart disease, 252 were eligible for examination, and 126 underwent further cardiological assessment, including 43 with SSHF.

Main outcome measures-Prevalence of SSHF as defined by a modified Boston index, LVSD defined as an indirectly measured left ventricular ejection fraction $\leqslant 0.45$, and numbers of subjects needing an echocardiogram to detect one case with LVSD.

Results-SSHF afflicted $0.5 \%$ of quadragenarians and rose to $11.7 \%$ of octogenarians. Two thirds were handled in primary care only. At $\geqslant 50$ years of age $6.4 \%$ had SSHF, $2.9 \%$ had LVSD, and $1.9 \%$ (95\% confidence interval $1.3 \%$ to $2.5 \%$ ) had both. To detect one case with LVSD in primary care, 14 patients with evidence of heart disease without SSHF and 5.5 patients with SSHF had to be examined.

Conclusion-SSHF is extremely prevalent in the community, especially in primary care, but more than two thirds do not have LVSD. The number of subjects with some evidence of heart disease needing an echocardiogram to detect one case of LVSD is 14 .

(Heart 2001;86:172-178)
\end{abstract}

Keywords: heart failure; left ventricular systolic dysfunction

Several mortality trials have provided evidence for the use of angiotensin converting enzyme (ACE) inhibitor, $\beta$ blocker, and spironolactone treatment in patients with congestive heart failure caused by left ventricular systolic dysfunction (LVSD). Although the data supporting the use of these drugs for this indication are compelling, the patients studied in these trials were highly selected and recruited from hospital populations. Serious questions have to be asked regarding whether these results can be extrapolated to primary care.

Epidemiological data suggest that heart failure occurs in about $2 \%^{12}$ of the population. Prevalence rates of over $10 \%$ have been reported in the very old..$^{3-5}$ However, studies on the validity of the diagnosis in primary care suggest that only $20-50 \%$ of these have definitive cardiac malfunction including the important subgroup with LVSD. ${ }^{6-10}$ One might therefore hypothesise that the number of patients who are eligible for the mortality trial treatment is two to three times less than epidemiological data suggest. At present, we have no data on the number of patients who are actually eligible for treatment in primary care.

Recently two large population based studies used echocardiography to determine the prevalence of LVSD in the community. ${ }^{11}{ }^{12}$ The prevalence was $2.9 \%$ in Glasgow and $3.7 \%$ in Rotterdam, but comparisons are hampered by use of different methods and criteria for assessing LVSD. For instance, the Glasgow prevalence rose to $7.7 \%$ if a left ventricular ejection fraction (LVEF) limit of 0.35 was used instead of 0.30 . About $1.5 \%$ in the Glasgow study had symptomatic LVSD. In clinical practice, however, only subjects who present with cardiopulmonary complaints can be examined for LVSD, usually by an echocardiogram or radionuclide/contrast ventriculogram.

Our strategy for detecting LVSD would therefore be to carry out echocardiography in a high risk population-for example, patients with signs and symptoms suggestive of heart failure (SSHF) or of heart disease..$^{11}{ }^{13}$ The outcome of using this strategy is not known although it is essential for estimating the likely impact of the trial results in clinical practice, the resources required for their implementation, and whether screening for LVSD would be appropriate. The number of patients eligible for the trial treatment can be estimated by investigating such a high risk population, which was the aim of the present study.

We undertook a screening of a general practice population to identify subjects with SSHF or heart disease. They were further evaluated by cardiac assessment including echocardiography. On the basis of this information, we calculated the number of subjects in the community with a suspected diagnosis of heart failure and with LVSD. 
Table 1 Principal cardiac diagnoses according to severity in patients over 50 years of age

\begin{tabular}{|c|c|c|c|c|c|}
\hline ICD code & Short description & $\begin{array}{l}\text { Non-responder } \\
(n=230) \\
(\%)\end{array}$ & $\begin{array}{l}\text { Responder } \\
(n=1367) \\
(\%)\end{array}$ & $\begin{array}{l}\text { Nursing home } \\
(n=158) \\
(\%)\end{array}$ & $\begin{array}{l}\text { Total } \\
(n=1755) \\
(\%)\end{array}$ \\
\hline \multicolumn{6}{|c|}{ Definite heart disease } \\
\hline I25.9 & Previous MI and angina & $2(0.9)$ & $32(2.3)$ & $0(0.0)$ & $34(1.9)$ \\
\hline I21.9 & Previous MI & $1(0.4)$ & $23(1.7)$ & $6(3.8)$ & $30(1.7)$ \\
\hline I20.9 & Angina pectoris & $9(3.9)$ & $31(2.3)$ & $4(2.5)$ & $44(2.5)$ \\
\hline I 48.9 & Atrial fibrillation & $5(2.2)$ & $21(1.5)$ & $5(3.2)$ & $31(1.8)$ \\
\hline I 37.0 & Pulmonary valve stenosis & $0(0.0)$ & $1(0.1)$ & $0(0.0)$ & $1(0.1)$ \\
\hline $\mathrm{I} 35.2$ & Aortic stenosis & $0(0.0)$ & $4(0.3)$ & $1(0.6)$ & $5(0.3)$ \\
\hline I 34.0 & Mitral insufficiency & $0(0.0)$ & $2(0.1)$ & $0(0.0)$ & $2(0.1)$ \\
\hline I11.9 & Hypertensive heart disease & $4(1.7)$ & $79(5.8)$ & $1(0.6)$ & $84(4.8)$ \\
\hline \multicolumn{6}{|c|}{ Suspected heart disease } \\
\hline I 49.8 & Pacemaker & $0(0.0)$ & $9(0.7)$ & $1(0.6)$ & $10(0.6)$ \\
\hline $\mathrm{I} 52.8$ & Secondary heart disease & $2(0.9)$ & $15(1.1)$ & $2(1.3)$ & $19(1.1)$ \\
\hline I5 51.7 & Cardiomegali on $x$ ray & $1(0.4)$ & $5(0.4)$ & $2(1.3)$ & $8(0.5)$ \\
\hline I26.9 & Pulmonary embolus & $0(0.0)$ & $3(0.2)$ & $0(0.0)$ & $3(0.2)$ \\
\hline $\mathrm{I} 27.9$ & Cor pulmonale & $2(0.9)$ & $13(1.0)$ & $0(0.0)$ & $15(0.9)$ \\
\hline I47.9 & Paroxysmal supraventricular tachycardia & $1(0.4)$ & $8(0.6)$ & $1(0.6)$ & $10(0.6)$ \\
\hline I51.8 & Unknown heart disease & $9(3.9)$ & $34(2.5)$ & $15(9.5)$ & $58(3.3)$ \\
\hline \multicolumn{2}{|c|}{ Any sign of heart disease } & $36(15.7)$ & $280(20.5)$ & $38(24.1)$ & $354(20.2)$ \\
\hline \multicolumn{2}{|c|}{ No apparent heart disease } & $194(84.3)$ & $1087(79.5)$ & $120(75.9)$ & $1392(79.3)$ \\
\hline
\end{tabular}

ICD, International classification of diseases, 10th revision; MI, myocardial infarction

\section{Methods}

STUDY POPULATION

The study population was defined by asking the National Health Insurance Register for names and addresses of all subjects who were connected to three general practices in the Copenhagen municipality on three separate dates from 1993 to 1995 . This procedure draws a near random sample independently of previous health contacts because more than $97 \%$ of the population have an appointment with their health insurance that connects them to a specific primary care physician with free and unrestricted access to consultations. Practices were chosen because the four primary care physicians working there allowed us to have unlimited access to case notes and because they had used the same computer program for case notes during the previous 2-4 years (Docbase, Roskilde, Denmark). The required sample size was estimated to be around 2200 to obtain a standard error of about $0.5 \%$ on the prevalence estimate.

We included all subjects $\geqslant 50$ years of age from all three general practices $(n=1755)$ and all subjects aged 40-49 years from one of the practices $(n=403)$. In the Copenhagen municipality $30 \%$ of the total population (141 682 of 471300$)$ is $\geqslant 50$ years of age. ${ }^{14}$ The age and sex composition in the study population was not different from that of the entire Copenhagen municipality. There was no difference between the studied districts and the entire Copenhagen municipality with respect to certain socioeconomic parameters (unemployment, social support, and average duration per hospital admission).

CROSS SECTIONAL SCREENING PROCEDURE

Screening was based on case record reviews and questionnaires. One research fellow in cardiology (OWN) reviewed all 2158 general practice case notes for cardiac history. Further information was obtained from hospital discharge letters and in some cases by requesting hospital records. A questionnaire sent to all subjects outside nursing homes $(n=2000)$ asked about dyspnoea, ${ }^{15}$ angina, ${ }^{15}$ and previous symptoms, treatment, or hospitalisation for heart trouble. Non-responders received a single reminder. We conducted telephone interviews with almost 500 subjects who had reported cardiac symptoms or disease in the questionnaire. The study was approved by the local ethical committee (appraisal No 01-086/ 95) and all examined patients gave informed consent.

DEFINITIONS IN CROSS SECTIONAL SURVEY

On the basis of the screening information anyone with past or present signs or symptoms of heart disease was allocated to one of the principal cardiac diagnoses ${ }^{16}$ in table 1 , after discussion between OWN and a consultant cardiologist $(\mathrm{JFH})$. Classifications used in this study were as follows.

Definite heart disease required objective evidence of heart disease-for example, echocardiography, catheterisation, stress test, cardiac scintigraphy, hospital admission for myocardial infarction, typical angina pectoris in the Rose questionnaire, ${ }^{15}$ and atrial fibrillation. Hypertensive heart disease was defined as a history of hypertension combined with a suspected type of heart disease (International classification of diseases, 10 th revision (ICD-10) code i51.7, i26.9, i27.9, i47.9, or i51.8).

Suspected heart disease appears from ICD-10 codes in table 1. Unknown heart disease (i51.8) was defined as unexplained or unknown reasons for atypical chest pain, SSHF (defined below), palpitations, abnormal ECG, hospital admission to a coronary care unit, and cardiovascular treatment. Secondary heart disease (i52.8) was unknown heart disease in a patient with concurrent chronic diseases.

No apparent heart disease was defined as no definite or suspected heart disease or heart failure.

Signs and symptoms of heart failure (SSHF) were noted if a physician in primary or secondary care had recorded such symptoms and treated or admitted the patient accordingly. The signs and symptoms, as inferred from the case records, should score $\geqslant 5$ points in the modified version of the Boston index (table 2). ${ }^{17}$ The index had to be modified because case records did not systematically grade 
Table 2 Boston index for evaluating signs and symptoms of heart failure (SSHF)

\begin{tabular}{ll}
\hline Category & Point \\
\hline I: History from questionnaire or case record & \\
Rest dyspnoea, orthopnoea & 4 \\
Paroxysmal nocturnal dyspnoea & 3 \\
Dyspnoea on walking on level & 2 \\
Dyspnoea on climbing & 1 \\
II: Physical examination from case record & \\
If heart rate > 91 to 110 beats/min & 1 \\
If heart rate >110 beats/min & 2 \\
Neck vein distension, hepatomegaly or leg oedema & 2 \\
Lung crackles & 2 \\
Wheezing & 3 \\
Third heart sound & 3 \\
III: Chest radiography from case record & \\
Alveolar pulmonary oedema & 4 \\
Interstitial pulmonary oedema & 3 \\
Bilateral pleural effusions & 3 \\
Cardiothoracic ratio > 0.49 & 2 \\
Upper zone flow redistribution & 1
\end{tabular}

Patients with suspected or definite heart disease were evaluated by this index if they had been treated or referred for heart failure. The sum within each category contributed at most four points to the composite score. SSHF was a composite score of $\geqslant 5$ points.

dyspnoea, neck vein distension, hepatomegaly, or leg oedema. The questionnaire alone could not classify SSHF but it gave supportive data on dyspnoea if these were lacking in the case records.

Managed in primary care was defined as a diagnosis of and treatment for SSHF in primary care only.

Known LVSD was information of "moderately or severely impaired systolic function" or an LVEF below 0.4 in case notes or discharge letters.

ECHOCARDIOGRAPHY IN STUDY POPULATION Of 357 patients with definite or suspected heart disease, 126 were included in the echocardiographic study phase. The purpose of the echocardiography was to identify LVSD in heart patients from primary care who were interested in attending, and able to attend, an ambulant cardiological examination. We excluded subjects in nursing homes, non-responders, and patients receiving inpatient or outpatient treatment for advanced heart failure. There was no upper age limit. Patients were offered free transportation and they spent at least four hours at the hospital to complete supplementary investigations. They were advised that all investigations were being performed as part of a research study.

Each patient underwent a comprehensive echocardiographic examination where $M$ mode, cross sectional (two dimensional), and Doppler images including left ventricular diastolic filling parameters were recorded by one of the investigators (OWN). Recorded echocardiograms and videotapes were later analysed by OWN, who was blinded to other patient data, and a sample of echocardiograms was validated by an independent experienced operator (CTL). Definitions were as follows.

$L V E F$ was indirectly estimated from fractional shortening as the median of five cardiac cycles $^{18}{ }^{19}$ or, in the $38 \%$ (48 of 126) where M mode measurements were unattainable, from a nine segment model for assessing wall motion index score. This wall motion index score has a positive linear correlation with $\operatorname{LVEF}^{20}{ }^{21}$ where a score of 2.0 approximates LVEF of 0.60 while a score of 1.0 approximates LVEF of 0.30 .

LVSD was defined as a wall motion index score $\leqslant 1.5$ or a fractional shortening $<0.26$, approximately equal to $\mathrm{LVEF} \leqslant 0.45$. The standard deviation of a single LVEF estimate was equal for intraobserver variability and interobserver variability - that is, 0.05 ejection fraction units or a coefficient of variation of $8 \%$.

Other cardiac abnormalities were left ventricular hypertrophy ${ }^{22}$; LVEF between 0.45 and 0.55 ; valvar defects in the presence of left ventricular hypertrophy, dilated left atrium $(>45 \mathrm{~mm})$, or dilated left ventricle (> $60 \mathrm{~mm}$ ); and diastolic dysfunction, defined as two or more of three abnormal filling parameters (deceleration time $>0.224 \mathrm{~s}$, ratio of early to late diastolic filling velocity $<0.5$, isovolumetric relaxation time $>0.1 \mathrm{~s}$ ).

DATA HANDLING AND STATISTICAL ANALYSIS Screening divided the population into one of four distinct groups: group 1, no apparent heart disease; group 2, no SSHF but suspected or definite heart disease; group 3, SSHF in primary care only; and group 4, SSHF in secondary care. Prevalence data are presented as observed figures and calculated figures, as follows.

Observed figures in cross sectional survey refer to total of SSHF (total of groups 3 and 4 in part I of table 3). Observed figures in echocardiographic substudy refer to the percentage with LVSD of groups 2 and 3, and to the subgroup of group 4 that did not receive inpatient or outpatient treatment any more.

Calculated figures describe the prevalence of LVSD in primary and secondary care (part III of table 3). Here observed prevalence data from the cross sectional survey (part I, column f) were multiplied by percentages of LVSD from the echocardiographic substudy (part II, column $\mathrm{h}$ ). The assumptions were that group 1 had zero prevalence of LVSD; that groups 2 and 3 had a percentage of LVSD as determined in echocardiographic substudy; and that those in group 4 with known LVSD had 100\% of LVSD. The rest were ascribed a percentage of LVSD as group 4 in the echocardiographic substudy (part II, column h).

Ranked ICD-10 codes between the three groups in table 1 were compared by the Kruskal-Wallis test and mean LVEF between groups 2 to 4 (part II of table 3) were compared by analysis of variance. The computer package Statistica (Statsoft, Tulsa, Oklahoma, USA) was used for all calculations.

\section{Results}

CROSS SECTIONAL SURVEY

The study population comprised 2158 persons or $1.2 \%$ (1755 of 141682 ) of Copenhagen municipality's population $\geqslant 50$ years of age. No data were available in $2.5 \%$ (55 of 2158) who were coded as healthy. The questionnaire response rate was $86 \%$ (1504 of 1757) for subjects $<80$ years of age, while $48 \%$ (191 of 401 ) 


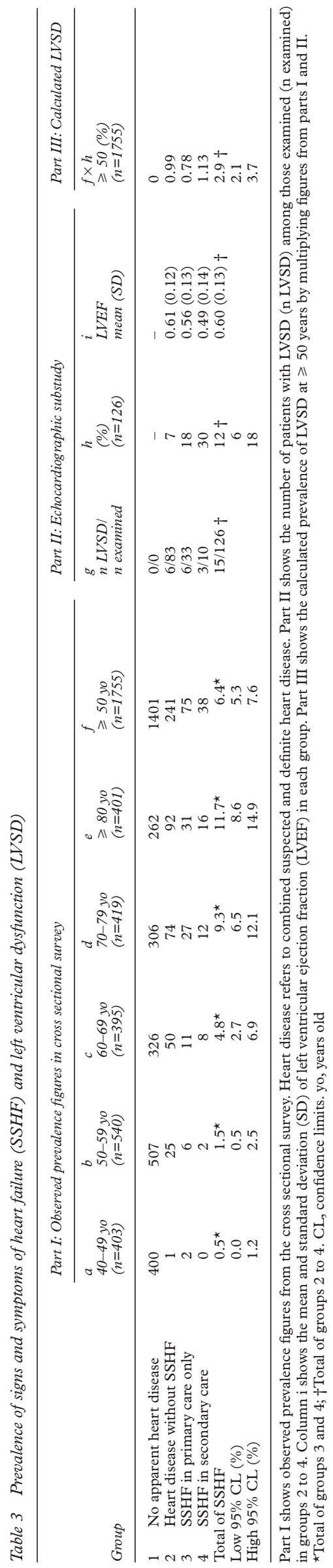

of subjects $\geqslant 80$ years were either nonresponders or nursing home patients.

Definite or suspected heart disease was identified in $354(20 \%$ of 1755$)$ subjects $\geqslant 50$ years of age (table 1) and in three subjects ( $0.7 \%$ of 403$)$ from $40-49$ years of age. No difference was documented in cardiac morbidity between non-responders and responders despite differences in data availability (KruskalWallis, $p=0.08$ ), but nursing home patients had a higher prevalence of suspected or unknown type of heart disease (Kruskal-Wallis, $\mathrm{p}=0.03)$.

Part I in table 3 shows how the total prevalence of SSHF rose with age and was $6.4 \%$ in subjects $\geqslant 50$ years of age. Of 38 patients with SSHF in secondary care (group 4) LVSD was known in only $12(\mathrm{n}=0,2,6,3$, and 1 for columns a, b, c, d, and e, respectively). Prior examination for LVSD in these groups was more frequently performed in patients $<70$ years of age ( 9 of 10) as opposed to $\geqslant 70$ years ( 7 of 28 ). At $\geqslant 50$ years of age, one third of groups 2 and 3 had suspected heart disease ( 80 of 241 and 29 of 75, respectively) as opposed to definite heart disease.

ECHOCARDIOGRAPHY

Of the 357 patients with some evidence of heart disease 105 were excluded and 126 of 252 eligible patients underwent echocardiography. The 105 patients were excluded by priority: 38 lived in nursing homes, 36 did not respond to the questionnaire, 21 without definite heart disease were excluded for administrative reasons in an early study phase, and 10 patients had advanced heart failure. Of the invited 252 patients, 126 dropped out: 32 declined the invitation, 1 died, 37 were disabled by various medical and psychosocial conditions, and 56 patients, after various degrees of contact, did not show up. The age of the 126 examined patients ranged from 49-93 years (5th and 95 th centiles, 53 and 83 years). Compared with the 126 patients not examined, those examined were younger (mean $70 v 77$ years of age, $p<0.001$ ) and more often had myocardial infarction $(30 v 10, \mathrm{p}<0.05)$ or angina pectoris $(37 v 16, \mathrm{p}<0.05)$, but there was no significant difference $(p>0.05)$ in the prevalence of atrial fibrillation (11 $v 19)$, hypertension (69 $v 62)$, diabetes (12 $v 23)$, chronic obstructive pulmonary disease (31 v 30), and sex (55 v 50 men). Echocardiography was performed in one patient $<50$ and 19 patients $\geqslant 80$ years of age. Of those dropping out $47 \%$ were $\geqslant 80$ years of age (59 of 126 ).

In part II echocardiography showed LVSD in 15 subjects among the 126 examined from groups 2-4 (column g, table 3 ). Their median LVEF was 0.35 (range $0.22-0.45$ ), ${ }^{24}$ and 10 patients had LVEF $\leqslant 0.40$. Mean LVEF decreased steadily from group 2 to group 4 (column I, table 3, analysis of variance, $\mathrm{p}=0.002$ ) while the prevalence of LVSD increased (column $\mathrm{h}$ ).

In patients without SSHF (group 2), the number of subjects needing an echocardiogram to detect one case of LVSD was 14 $(83 / 6)$. Definite heart disease $(n=69)$, but not 
SSHF

in primary care

$4.3 \%$

SSHF

in secondary care

$2.1 \%$

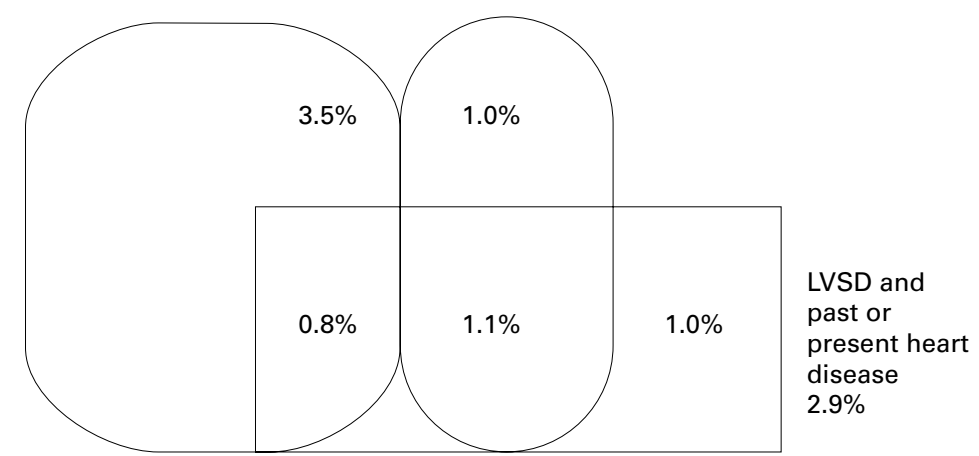

Figure 1 Relation between signs and symptoms of heart failure (SSHF) and left ventricular systolic dysfunction (LVSD) in primary and secondary care. Ellipses show the $6.4 \%$ prevalence of observed SSHF in primary and secondary care at $\geqslant 50$ years of age. The square shows the calculated prevalence of LVSD. Overlapping areas reflect the prevalence of patients with both SSHF and LVSD.

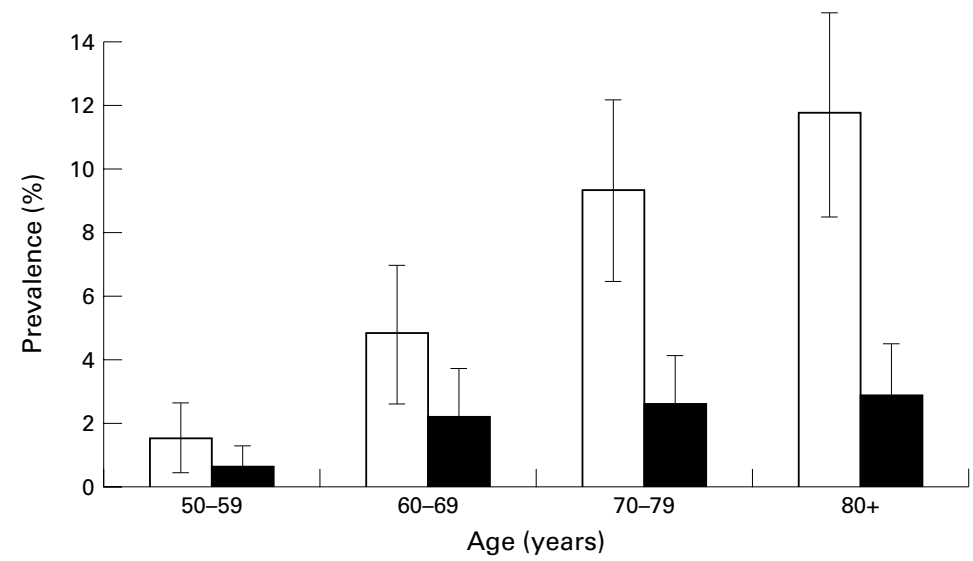

Figure 2 Age dependent prevalence of signs and symptoms of heart failure (SSHF) and its subgroup with left ventricular systolic dysfunction (LVSD). Empty bars show the observed prevalence of SSHF (groups $3+4$ in part I of table 3). Solid bars show the subgroup with SSHF and calculated LVSD at same age band. $95 \%$ confidence limits are indicated. is straightforward for groups 2 and $3((6 / 83) \times$ $(241 / 1755)$ and $(6 / 33) \times(75 / 1755))$. The calculation for group 4 had to account for those 12 with known LVSD $(1.13 \%=12 / 1755+$ $((38-12) \times 0.3) / 1755)$. If $0.3 \mathrm{had}$ been replaced by such extreme values as $0 \%$ or $100 \%$, then group 4 would have contributed with $0.7 \%$ (12 of 1755 ) or $2.1 \%$ (38 of 1755) instead of $1.13 \%$. Alternative calculations for total prevalence were tried: a non-stratified calculation, instead of using four groups, yielded a total prevalence of $2.4 \%((1755-1401) / 1755 \times$ $(15 / 126))$; a seven group calculation, subdivided by suspected and definite heart disease, yielded a total prevalence of $2.7 \%$. All alternatives gave estimates within the calculated confidence limits (columns $f \times h$, table 3 ).

Figure 1 illustrates the relations between LVSD, SSHF, and management in secondary and primary care. The figure combines data from parts I and III in table 3 (column $f$ and $f \times$ h). LVSD occurred in less than one third of SSHF. One third of SSHF patients had been managed in secondary care. Half of these had LVSD. Asymptomatic LVSD among patients with evidence of heart disease afflicted $1 \%$ corresponding to $34 \%(1 / 2.9)$ of all with LVSD. Obviously our strategy did not include subjects who never presented a sign of heart disease. Supplementary analyses revealed that the ratio of LVSD to SSHF differed for older and younger subjects.

Figure 2 highlights the age dependent relation between SSHF and its subgroup with symptomatic LVSD. The figure is constructed by calculating LVSD in groups 3 and 4 while accounting for known LVSD at each age band. Figure 2 suggests that LVSD is more likely to be the cause of SSHF in younger than in older patients. The proportion with LVSD was $43 \%$ of SSHF patients $<70$ years of age as opposed to $25 \%$ of SSHF patients $\geqslant 70$ years of age $(\mathrm{p}<0000.1)$.

suspected heart disease $(\mathrm{n}=14)$, affected all six patients with LVSD.

Of those with SSHF in primary care (group 3 ), half the patients (16 of 33) had no abnormalities on full cardiac assessment. One fifth (6 of 33) had LVSD, four had significant valvar disease and seven had other cardiac abnormalities. Thus the number of SSHF subjects in primary care (group 3) needing an echocardiogram to detect one case of LVSD was $5.5(33 / 6)$. The six patients with LVSD in group 3 were found among 23 with definite heart disease $(n=5)$ and among 10 with suspected heart disease $(n=1)$.

Of those with SSHF in secondary care (group 4), three patients had LVSD and the remaining seven had other cardiac abnormalities. The 30\% (3 of 10) frequency of LVSD (column h) is somewhat artificial because it is based on a mix of patients with and without known LVSD. The four patients with known LVSD were included because they are now managed in primary care.

Part III of table 3 shows that $2.9 \%$ of the population at $\geqslant 50$ years of age have LVSD and some evidence of heart disease. The calculation

\section{Discussion}

MAIN FINDINGS

This study examined subjects with some evidence of heart disease in primary care and found that, of subjects $\geqslant 50$ years of age, $6.4 \%$ had SSHF, $2.9 \%$ had LVSD, and $1.9 \%$ had both SSHF and LVSD. The number of subjects with evidence of heart disease needing an echocardiogram to detect one case of LVSD was 14 . This number was 5.5 in SSHF patients from primary care.

\section{PREVIOUS WORK}

Several prevalence studies of heart failure have been reported, but the present one is the first to use a clinically pragmatic screening procedure along with echocardiography. The present study's SSHF prevalence was 30\% higher than in the Framingham heart study, ${ }^{4}$ probably because of more liberal criteria. In contrast, the Gothenburg study showed a much higher prevalence rate in 67 year old men (of $13 \%$ ) by still more liberal criteria. ${ }^{3}$ Prevalence rates from the present study, Rotterdam, ${ }^{12}$ and Liverpool ${ }^{5}$ were similar and higher than those reported in 
one study from London that probably interpreted the diagnostic criteria more strictly. ${ }^{25}$ The London study's prevalence was $0.6 \%$ under and $2.8 \%$ over 65 years of age, which are comparable with the present study's secondary care based prevalence of SSHF. All studies illustrate the vast number of patients with suspected heart failure who would need a diagnostic echocardiogram to identify the existence and type of underlying cardiac pathology, some of whom would have LVSD.

The calculated $1.9 \%$ prevalence of combined SSHF and LVSD in the present study can be compared with $1.5 \%$ in the Glasgow study, although our estimate refers to subjects $\geqslant 50$ as opposed to $25-75$ years in the Glasgow study. On the basis of data from the Helsinki aging study, $8.2 \%$ of subjects aged $75-86$ had symptomatic heart failure but $70 \%$ had normal systolic function. ${ }^{26}$ Thus the resulting prevalence of symptomatic LVSD was $2.4 \%$. The Framingham study reported a $4.9 \%$ and $9.1 \%$ prevalence of symptomatic heart failure at 70-79 and 80-89 years of age, respectively. ${ }^{4} \mathrm{~A}$ subsequent study reported that $49 \%$ of Framingham's patients with heart failure (mean age 73) had LVSD. ${ }^{27}$ This makes for a $2.4 \%$ and $4.4 \%$ prevalence of symptomatic LVSD at $70-79$ and $80-89$ years of age, respectively. Figure 2 is therefore in concert with previous studies with one exception. The calculated $4.4 \%$ prevalence at age $80-89$ in Framingham is substantially higher than that reported in this and other studies. The difference may reflect the prospective design of the Framingham study, which ensured detection of elderly patients with a very short survival who cannot be detected in a cross sectional design with a retrospective case identification. An alternative explanation is that patients $>80$ years old with congestive heart failure have less than the mean $49 \%$ LVSD. Wheeldon and colleagues ${ }^{6}$ concluded, from a general practice study, that the population prevalence of combined symptomatic heart failure and LVSD was $0.84 \%$. A comparable figure of $0.6 \%(0.3 \times 1.9 \%)$ can be derived from the present study as $30 \%$ of the population was aged $\geqslant 50$ years and by assuming zero prevalence in subjects $<50$ years.

The present study's prevalence estimates for total (symptomatic and asymptomatic) LVSD is the same as that of Morgan and colleagues ${ }^{13}$ for comparable ages and LVEF values. ${ }^{13}$ Our total $2.9 \%$ prevalence relates to $2.9 \%$ in the Glasgow and $3.7 \%$ in Rotterdam studies. ${ }^{11}{ }^{12}$ Comparison is, however, hampered by differences in the methods and limits used for assessing LVSD between studies. The Glasgow study used Simpson's rule with biplane echocardiography and the Rotterdam study used $\mathrm{M}$ mode echocardiograms and a fractional shortening $\leqslant 0.25$ for LVSD. Unlike epidemiological surveys, the present study ignored further assessment of subjects without apparent heart disease. These methodological aspects also affect the percentages with asymptomatic LVSD, which was $34 \%$ in the present study, $83 \%$ (50 of 60 ) in the Rotterdam study, and $48 \%$ in the Glasgow study using an LVEF limit of 0.30 but $77 \%$ when a limit of 0.35 was used.
STUDY STRENGTHS AND LIMITATIONS We are confident about the validity of the present study because some of the calculated figures reproduce data from other studies, such as the frequency of LVSD in hospitalised heart failure patients, ${ }^{28}$ in general practice, ${ }^{78}{ }^{10}$ and in a high risk group similar to our group $2 .{ }^{29}$ Only a few patients with significant symptoms of heart failure could have escaped our liberal criteria and careful screening procedure. We aimed for correct classification by having a research fellow in cardiology scrutinise medical records, interview subjects, and categorise all diagnoses, a procedure that would have been tedious in a larger population and without electronic records. Heart failure diagnosis is fraught with difficulties ${ }^{1}$ and the present classification, though careful in each case, was not validated by an independent observer who might have classified a few subjects differently.

LVSD prevalence was calculated in four strata of the general practice clientele to correct for differences in frequency of heart disease and SSHF between the screened population and the echocardiographic sample population. The calculation assumed that all patients in a group were comparable with the same risk of LVSD. This was not proved, and the calculation may have underestimated the prevalence of LVSD if the unexamined patients were more diseased and had more LVSD. There was no direct adjustment for sex, hypertension, or diabetes. These are important risk factors for myocardial infarction at the level of primary prevention, but may be less important risk factors for $\mathrm{LVSD}^{11}$ once heart disease has become clinically apparent. The echocardiographic substudy showed that all but one case of LVSD were found in patients with prior definite rather than suspected heart disease.

We had intended to obtain an echocardiogram for all with some evidence of heart disease but many, especially elderly, subjects were unwilling to attend our hospital based echocardiographic clinic. We did not systematically examine their reasons for declining but it is our opinion that physical disability and psychological factors such as anxiety in regard to disease and hospitals were important. In contrast Morgan and colleagues ${ }^{13}$ obtained echocardiograms in $68 \%$ (817 of 1200) of a random sample of patients aged $70-84$ years when they were examined in their homes.

\section{WHAT IT MEANS FOR PRACTICE}

These results are important when discussing the diagnostic and therapeutic needs of modern heart failure management. It is still, after the HOPE (heart outcomes prevention evaluation) study, $^{29}$ important to try to identify subjects with LVSD and SSHF because they have a greater morbidity and poorer prognosis, and benefit particularly from the trial treatment. About $1.9 \%$ of the population $\geqslant 50$ years of age have symptomatic LVSD and should match inclusion criteria as used in the mortality trials. However, the number of patients eligible for trial treatment may be lower considering the contraindications for treatment, that an ejection fraction limit of 
$0.35-0.40$ was used in the mortality trials as opposed to the 0.45 ejection fraction limit in the present study, and that access to echocardiography may be limited in clinical practice.

Thus, the need for echocardiographic service is huge if one is to provide individually guided treatment to those $6.4 \%$ of subjects with SSHF $\geqslant 50$ years of age, especially as a service to primary care. The need for this service detecting LVSD in asymptomatic heart patients is even greater because 14 echocardiograms are required to detect one case. Screening high risk patients, especially those with definite heart disease, by simple measurements of ECG, natriuretic peptides, simplified echocardiography, or simple clinical decision rules ${ }^{24}$ 30-33 holds promise, although studies that show the cost effectiveness of this approach are not yet available.

It is our experience that it may be troublesome to detect LVSD in subjects over 80 years of age because they are less willing to participate in a screening programme. Future studies should provide a better understanding of the pathophysiology of heart failure in the elderly and define useful treatment strategies for the many patients with symptoms ascribed to heart failure without LVSD. Meanwhile, studying survival in the various groups of this study would indicate where additional efforts are needed. The six to eight year follow up is taking place in 2001 .

We thank the patients and general practitioners Hans FrimodtMøller, Hans-Christian Møller, Christen Myrup, and Erik Schiøttz-Christensen for kindly and unreservedly placing their
general practice case notes at our disposal. The study was supgeneral practice case notes at our disposal. The study was suppraksis I København, Frederiksberg, Tårnby kommuner.

1 Cowie MR, Mosterd A, Wood DA, et al. The epidemiology of heart failure. Eur Heart 7 1997;18:208-25.

2 Schocken DD, Arrieta MI, Leaverton PE, et al. Prevalence and mortality rate of congestive heart failure in the United and mortality rate of congestive heart fail

3 Eriksson H, Svardsudd K, Caidahl K, et al. Early heart failure in the population. The study of men born in 1913. Acto Med Scand 1988;223:197-209.

4 Kannel WB, Belanger AJ. Epidemiology of heart failure. $A m$ Heart 7 1991;121:951-7.

5 Mair FS, Crowley TS, Bundred PE. Prevalence, aetiology and management of heart failure in general practice. $B r \mathcal{F}$ Gen Pract 1996;46:77-9.

6 Wheeldon NM, MacDonald TM, Flucker CJ, et al. Echocardiography in chronic heart failure in the community. Q F Med 1993;86:17-23.

7 Remes J, Miettinen H, Reunanen A, et al. Validity of clinical diagnosis of heart failure in primary health care [see comments]. Eur Heart $\mathcal{f} 1991 ; 12: 315-21$.

8 Dahlstrom U, Boman K, Edvardsson N, et al. [Heart failure: Dahlstrom U, Boman K, Edvardsson $\mathrm{N}$, et al. [Heart failure: difficult to diagnose. Can a point system
patients?] Lakartidningen 1995;92:1360-3.

9 Cowie MR, Wood DA, Coats AJ, et al. Incidence and aetiology of heart failure; a population-based study. Eur aetiology of heart failu

10 Francis CM, Caruana L, Kearney P, et al. Open access echocardiography in management of heart failure in the community. BMF 1995;310:634-6.
11 McDonagh TA, Morrison CE, Lawrence A, et al. Symptomatic and asymptomatic left-ventricular systolic dysfunction in an urban population. Lancet 1997;350:829-33.

12 Mosterd A, Hoes AW, de Bruyne MC, et al. Prevalence of heart failure and left ventricular dysfunction in the general population: The Rotterdam study. Eur Heart f 1999;20: 447-55.

13 Morgan S, Smith H, Simpson I, et al. Prevalence and clinical characteristics of left ventricular dysfunction among elderly patients in general practice setting: cross sectional survey. BMF 1999;318:368-72.

14 Københavns statistiske kontor. Statistisk årbog for København og Frederiksberg samt Hovedstadsregionen 1995. 74 th ed. Copenhagen: Københavns statistiske kontor; 1995.

15 Rose GA, Blackburn H. Cardiovascular survey methods. Monograph series. Geneva: World Health Organization $1968 ; 56: 1-188$.

16 WHO. International statistical classification of diseases and health related problems (ICD). Copenhagen: Sundhedstyrelesn og Munksgaard, 1993.

17 Carlson KJ, Lee DC, Goroll AH, et al. An analysis of physicians' reasons for prescribing long-term digitalis therapy in outpatients. 7 Chronic Dis 1985;38:733-9.

18 Quinones MA, Waggoner AD, Reduto LA, et al. A new, simplified and accurate method for determining ejection fraction with two-dimensional echocardiography. Circulation 1981;64:744-53.

19 Sahn DJ, DeMaria A, Kisslo J, et al. Recommendations regarding quantitation in M-mode echocardiography: results of a survey of echocardiographic measurements. Circulation 1978;58:1072-83.

20 Berning J, Rokkedal NJ, Launbjerg J, et al. Rapid estimation of left ventricular ejection fraction in acute myocardial infarction by echocardiographic wall motion analysis. Cardiology 1992;80:257-66.

21 Kober L, Torp-Pedersen C, Carlsen J, et al. An echocardiographic method for selecting high risk patients shortly after acute myocardial infarction, for inclusion in multi-centre acute myocardial infarction, for inclusion in multi-centre
studies (as used in the TRACE study). Trandolapril cardiac evaluation. Eur Heart f 1994;15:1616-20.

22 Levy D, Savage DD, Garrison RJ, et al. Echocardiographic criteria for left ventricular hypertrophy: the Framingham heart study. Am f Cardiol 1987;59:956-60.

23 Troy BL, Pombo J, Rackley CE. Measurement of left ventricular wall thickness and mass by echocardiography. Circulation 1972;45:602-11.

24 Nielsen OW, Hansen JF, Hilden J, et al. Risk assessment of left ventricular systolic dysfunction in primary care: cross sectional study evaluating a range of diagnostic tests. $B M \mathcal{F}$ 2000;320:220-4.

25 Parameshwar J, Shackell MM, Richardson A, et al. Prevalence of heart failure in three general practices in Prevalence of heart failure in three general practice
north west London. Brf Gen Pract 1992;42:287-9.

26 Kupari M, Lindroos M, Iivanainen AM, et al. Congestive heart failure in old age: prevalence, mechanisms and 4-year prognosis in the Helsinki ageing study. F Intern Med 1997; 241:387-94.

27 Vasan RS, Larson MG, Benjamin EJ, et al. Congestive heart failure in subjects with normal versus reduced left ventricular ejection fraction: prevalence and mortality in a population-based cohort. F Am Coll Cardiol 1999;33:194855 .

28 Madsen BK, Hansen JF, Stokholm KH, et al. Chronic congestive heart failure: description and survival of 190 consecutive patients with a diagnosis of chronic congestive heart failure based on clinical signs and symptoms. Eur Heart $\mathcal{7}$ 1994;15:303-10.

29 Yusuf S, Sleight P, Pogue J, et al. Effects of an angiotensinconverting-enzyme inhibitor, ramipril, on cardiovascular events in high-risk patients. The heart outcomes prevention evaluation study investigators. N Engl f Med 2000;342:14553.

30 Cowie MR, Struthers AD, Wood DA, et al. Value of natriuretic peptides in assessment of patients with possible new heart failure in primary care. Lancet 1997;350:1349-53.

$31 \mathrm{McD}$ onagh TA, Robb SD, Murdoch DR, et al. Biochemical detection of left-ventricular systolic dysfunction. Lancet 1998;351:9-13.

32 Davie AP, Francis CM, Love MP, et al. Value of the electrocardiogram in identifying heart failure due to left ventricular systolic dysfunction. BMF 1996;312:222

33 Willenheimer RB, Israelsson BA, Cline CM, et al. Simplified echocardiography in the diagnosis of heart failure. Scand Cardiovasc $\mathcal{F}$ 1997;31:9-16. 